\title{
Post-Operative Drop in Hemoglobin and Need of Blood Transfusion in Cesarean Section at Dhulikhel Hospital, Kathmandu University Hospital
}

\author{
Singh $B,{ }^{1}$ Adhikari $N,{ }^{2}$ Ghimire $S,{ }^{3}$ Dhital $S^{4}$
}

\author{
${ }^{1}$ Department of Nursing \\ ${ }^{2}$ Department of Community Program \\ ${ }^{3}$ Department of Pharmacology \\ ${ }^{4}$ Department of Anatomy \\ Dhulikhel Hospital-Kathmandu University Hospital \\ Dhulikhel , Kavre \\ Nepal \\ Corresponding author \\ Bishnu Singh \\ Department of Nursing \\ Dhulikhel Hospital-Kathmandu University Hospital \\ Dhulikhel, Kavre, Nepal \\ Email: bishnu.singh@yahoo.com

\section{Citation} \\ Singh B, Adhikari N, Ghimire S, Dhital S. Post- \\ Operative Drop in Hemoglobin and Need of Blood \\ Transfusion in Cesarean Section at Dhulikhel Hospital, \\ Kathmandu University Hospital. Kathmandu Univ Med J \\ 2013;42(2):144-146.
}

\begin{abstract}
Background

Cesarean section has been identified as one of the commonest indication for blood transfusion in obstetric practice because it involves risk of major intra-operative blood loss. Different figures varying from less than $500 \mathrm{ml}$ to more than $1000 \mathrm{ml}$ have been quoted as estimated blood loss associated with caesarean section. There is also a wide variation in blood ordering practices for this surgery.
\end{abstract}

\section{Objective}

The objective of this study is to evaluate the blood ordering practice and transfusion for cesarean sections at our institute, to see post-operative drop in hemoglobin and hematocrit and to correlate those parameters with the duration between uterine incision and repair.

\section{Methods}

In this prospective observational study, non-randomised purposive sample was taken from 121 ladies who underwent elective and emergency cesarean section at the department of obstetrics of Dhulikhel Hospital-Kathmandu University Hospital. Post-cesarean drop in hemoglobin and hematocrit and their relation with duration of uterine manipulation was calculated. Cross-match to transfusion ( $C / T$ ratio) ratio, transfusion probability (\%T) and transfusion index (Ti) were also calculated.

\section{Results}

Most frequent blood group was found to be 0 positive (38\%) among those ladies. Average post-cesarean drop in hemoglobin was $1.52 \pm 1.27 \mathrm{gm} / \mathrm{dl}$ and drop in haematocrit was $5.49 \pm 4.1 \%$. Post-operative drop in hemoglobin and haematocrit had weak and positive linear relation with duration between uterine incision and repair. Cross-match to transfusion ratio was 1 , transfusion probability $100 \%$ and transfusion index was 2 .

\section{Conclusion}

There is no need of routine cross-matching of blood for cesarean section. Only grouping with confirmation of availability should be done for emergency situation.

\section{KEY WORDS}

Blood transfusion, cesarean Section, drop in hemoglobin

\section{INTRODUCTION}

Obstetric hemorrhage is among leading causes of direct maternal mortality in obstetric practice. ${ }^{1}$ It is major contributor to maternal mortality in developing countries. ${ }^{2}$ Cesarean section has been identified as one of the commonest indication for blood transfusion in obstetric practice because it involves risk of major intra-operative blood loss. ${ }^{3}$ Different figures varying from less than 500 $\mathrm{ml}$ to more than $1000 \mathrm{ml}$ have been quoted as estimated blood loss associated with caesarean section. There is also a wide variation in blood ordering practices for this surgery. Over the last few years there has been growing concern for safety, cost and adequacy of blood utilization. ${ }^{4}$
Evidence-based health policies and programs aiming to reduce maternal deaths need reliable and valid information. ${ }^{2}$ The aim of this study is to enable improvements in patient experience on blood utilization as a result of a successful audit cycle.

The objective of this study is to evaluate the blood ordering practice and transfusion for cesarean sections at our institute, to see post-operative drop in hemoglobin and hematocrit and to correlate the postoperative drop in those parameters with the duration between uterine incision and repair. 


\section{METHODS}

After getting approval from institutional review committee for this prospective observational study, non-randomised purposive sample of 121 ladies who underwent elective and emergency cesarean section at the department of obstetrics of Dhulikhel Hospital-Kathmandu University Hospital from $9^{\text {th }}$ September 2011 to $11^{\text {th }}$ March 2012 were enrolled in the study. Ladies with normal haemostasis profile were included in the study, those with abnormal bleeding profile or on anticoagulant therapy were excluded. The paramaters included age of the lady, type of cesarean section whether elective or emergency, time of uterus incision and uterus repair to calculate duration in between, preoperative hemoglobin and haematocrit, bleeding time and clotting time to exclude the lady with abnormal reading, blood group, number of blood units arranged and cross-matched preoperatively for the lady and the units transfused intraoperative or postoperative. 'Blood arranged' refer to only blood grouping and hold order to blood bank. Postoperative hemoglobin and haematocrit was done at 48 hours post cesarean. The data collected was analyzed using Statistical Program for social Sciences (SPSS) V 17.0. Cross-match to transfusion (C/T ratio) ratio, transfusion probability $(\% \mathrm{~T})$ and transfusion index (Ti) were also calculated. (Table 1 )

\section{Table 1. Indicators of blood utilization.}

\begin{tabular}{l|l}
$\begin{array}{l}\text { Cross-match to Transfusion } \\
\text { ratio(C/T ratio) }\end{array}$ & No of units cross-matched \\
\hline Nransfusion Probability (\%T) & No. of patients transfused x 100 \\
\hline No. of patients cross-matched \\
\hline Nransfusion Index (Ti) & No. of units transfused \\
\hline No. of patients cross-matched
\end{tabular}

\section{RESULTS}

Mean age of the ladies included in the study was $24.54 \pm 4.27$ years ranging from 16 to 43 years. Among all, $72.7 \%$ ladies underwent emergency cesarean section whereas (27.3\%) underwent electively.

Most frequent blood group was found to be $\mathrm{O}$ positive (38\%) followed by B positive (27.3\%), A positive (25.6\%), $A B$ positive (8.3\%) and A negative (0.8\%). (Fig 1)

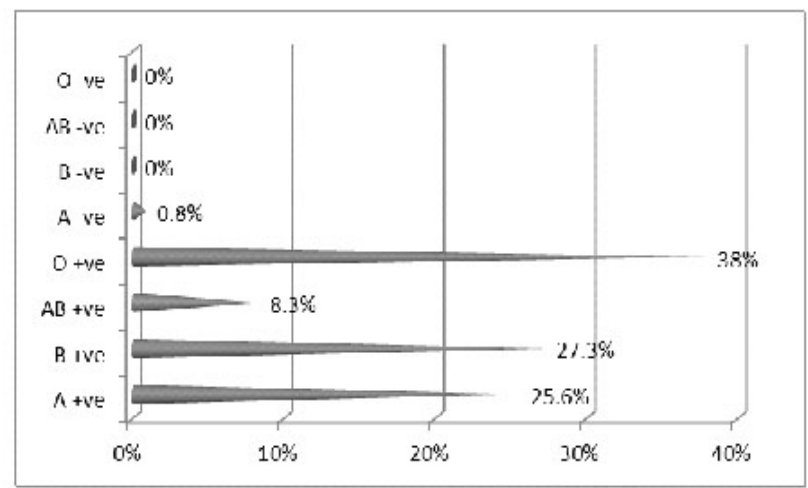

Figure 1. Frequency of blood group.
The average preoperative hemoglobin was $12.23 \pm 1.13$ $\mathrm{gm} / \mathrm{dl}$ ranging from $8.6 \mathrm{gm} / \mathrm{dl}$ to $15.6 \mathrm{gm} / \mathrm{dl}$. The average preoperative haematocrit was $39.36 \pm 3.98 \%$ ranging from 28 to $52 \%$. For the lady with lowest hemoglobin $(8.6 \mathrm{gm} /$ dl), 4 units of blood were arranged and 2 units of those were cross-matched preoperatively. Among the crossmatched, one unit was transfused intraoperatively and one unit postoperatively. Postoperative hemoglobin for this lady was again $8.6 \mathrm{gm} / \mathrm{dl}$ after receiving 2 units of blood transfusion. For remaining all 2 units were arranged and none cross-matched. Average time between uterus incision and repair was $10.01 \pm 6.76$ minutes. The average postoperative hemoglobin was $10.74 \pm 1.49 \mathrm{gm} / \mathrm{dl}$ and haematocrit $33.97 \pm 4.51 \%$. Average drop in hemoglobin was $1.52 \pm 1.27 \mathrm{gm} / \mathrm{dl}$ and drop in haematocrit was $5.49 \pm 4.1 \%$. Maximum hemoglobin dropped was $6.6 \mathrm{gm} / \mathrm{dl}$ (haematocrit 20\%) and minimum $0 \mathrm{gm} / \mathrm{dl}$ (haematocrit 0\%). Post-operative drop in hemoglobin had weak and positive linear relation with duration between uterine incision and repair $(r=0.056)$. Post-operative drop in haematocrit also showed similar relation $(r=0.083)$. Average drop in hemoglobin at emergency surgery was $1.58 \pm 1.36 \mathrm{gm} /$ $\mathrm{dl}$ (haematocrit $5.53 \pm 4.54 \%$ ) whereas at elective surgery it was $1.36 \pm 0.96 \mathrm{gm} / \mathrm{dl}$ (haematocrit $5.36 \pm 2.63 \%$ ). Crossmatch to transfusion ratio was 1 , transfusion probability $100 \%$ and transfusion index 2.

\section{DISCUSSION}

The indications for the caesarean section and quantity of blood loss during the surgery were significant risk factors for blood transfusion. Severe haemorrhage requiring blood transfusion can be predicted in majority of patients on the basis of antenatal risk factors. ${ }^{5}$ But accurate estimation of blood loss during this surgery is difficult because of dispersion of blood and blood being mixed with amniotic fluid. Anaesthesiologists often rely on clinical estimation of blood loss alone to guide the transfusion of blood in the perioperative period because other methods of estimations either may not be practical or available at all the times. ${ }^{6}$

Although the incidence of severe transfusion reactions and infections is now very low, in recent years it has become apparent that there is an immunological price to be paid for the transfusion of blood products which leads to increased morbidity. ${ }^{7-10}$ Moreover blood is a finite resource with a limited shelf life and is associated with considerable processing costs. Therefor utilization of this resource needs critical review to identify areas of overuse and thus reduce risk to patient and hospital costs. Efforts should be made to reduce the blood transfusion without increasing maternal morbidity and mortality. ${ }^{5,6}$ Past literatures also suggest eliminating cross-matching for cesarean section in the absence of significant risk factors. ${ }^{11,12}$

Now the risk of transfusion in association with cesarean is low. However preoperative maternal anemia, placenta previa, haemorrhage, preeclampsia and HELLP syndrome are all associated with transfusion risk. ${ }^{11,13}$ It has been 
shown that a lady can withstand post-haemorrhagic haematocrit level of $20 \%$. Transfusion may be appropriate when hemoglobin is $7-10 \mathrm{gm} / \mathrm{dl}$ and there is active bleeding or associated co-morbidities. ${ }^{4}$ In our study also, only transfusion given was to a lady presenting with antepartum haemorrhage whose preoperative hemoglobin was 8.6 $\mathrm{mg} / \mathrm{dl}$. No transfusion was given for remaining three ladies whose preoperative hemoglobin was less than $10 \mathrm{gm} / \mathrm{dl}$.

Cross-match to transfusion ratio of 2.5 is considered as significant for blood usage. Similarly transfusion probability of $30 \%$ is considered indicative of significant blood usage. ${ }^{14}$ In our study values were 1 and 100\% respectively. Only two units of blood were cross-matched for a lady among 121 and both of them were utilized.

Post cesarean hemoglobin level in a lady depends upon various factors like amount of blood loss during the surgery, iron stored in the body during pregnancy, lactation and body mass index (BMI). Sudden hemorrhage may occur with any manipulation of the highly vascular term uterus. We tried to find out relation between the duration of uterine manipulation and post-operative drop in hemoglobin and haematocrit where both showed weak relation. Faponle et al also found similar result that the duration of surgery didn't have a statistical significant influence on blood transfusion. ${ }^{15}$ Studies showed that breast feeding was associated with a decrease risk of postpartum anemia whereas high pre-pregnancy BMI increases the risk. ${ }^{16,17}$

\section{CONCLUSION}

There is no need of routine cross-matching of blood for cesarean section. Only grouping with confirmation of availability should be done for emergency situation. However this surgical audit is institutional based, recommendation cannot be generalized.

\section{REFERENCES}

1. Clark SL, Belfort MA, Dildy GA, Herbst MA, Meyers JA, Hankins GD. Maternal death in the 21st century: causes, prevention, and relationship to cesarean delivery. American journal of obstetrics and gynecology 2008;199(1)36:31-36.

2. Khan KS, Wojdyla D, Say L, Gülmezoglu AM, Van Look PF. WHO analysis of causes of maternal death: a systematic. Lancet 2006, 367:1066-1074.

3. Matot I, Einav S, Goodman S, Zeldin A, Weissman C, Elchalal U. A survey of physicians' attitudes toward blood transfusion in patients undergoing cesarean section. American journal of obstetrics and gynecology 2004, 190(2):462.

4. Khan F, Khan M, Ali A, Chohan U. Estimation of blood loss during Caesarean section: an audit. JPMA The Journal of the Pakistan Medical Association 2006, 56(12):572.

5. Eusaph AZ, Iqbal S, Rana T, Asghar F. Evaluation of Practices of Blood Transfusion in Various Indication of Caesarean Section. Annals of King Edward Medical University 2011;17(2).

6. Ponniah NEDM. Perioperative Blood Loss Assessment- How Accurate? Indian Journal Of Anesthesia 2006:36.

7. Goodnough LT. Risks of blood transfusion. Critical care medicine 2003;31(12):678-S686.

8. Moore FA, Moore EE, Sauaia A. Blood transfusion: an independent risk factor for postinjury multiple organ failure. Archives of Surgery 1997;132(6):620.

9. Hill GE, Frawley WH, Griffith KE, Forestner JE, Minei JP. Allogeneic blood transfusion increases the risk of postoperative bacterial infection: a meta-analysis. The Journal of Trauma and Acute Care Surgery 2003;54(5):908-914.

10. Sandler S, Yu H, Rassai N. Risks of blood transfusion and their prevention. Clin Adv Hematol Oncol 2003;1(5):307-313.

11. Cousins LM, Teplick FB, Poeltler DM. Pre-cesarean blood bank orders: a safe and less expensive approach. Obstetrics \& Gynecology 1996;87(6):912-916.

12. Ness P, Rosche M, Barrasso C, Luff R, Johnson Jr J. The efficacy of type and screen to reduce unnecessary cross matches for obstetric patients. American journal of obstetrics and gynecology 1981;140(6):661.

13. Rouse DJ, MacPherson C, Landon M, Varner MW, Leveno KJ, Moawad $\mathrm{AH}$ et.al. Blood transfusion and cesarean delivery. Obstetrics \& Gynecology 2006;08(4):891.

14. Vibhute $M$, Kamath S, Shetty A. Blood utilisation in elective general surgery cases: requirements, ordering and transfusion practices. Journal of postgraduate medicine 2000;46(1):13.

15. Faponle A, Makinde O. Caesarean section: intra-operative blood loss and its restitution. East African Medical Journal 2007;84(1):31-34.

16. Chapel Hill N. High prevalence of postpartum anemia among lowincome women in the United States. Am J Obstet Gynecol 2001;185(2).

17. Bodnar LM, Siega-Riz AM, Cogswell ME. High prepregnancy BMI increases the risk of postpartum anemia. Obesity Research 2012; 12(6):941-948. 